\title{
A Shock-Induced Phase Change in Orthoclase ${ }^{1}$
}

\author{
Thomas J. Ahrens and Hsi-Ping Liu \\ Seismological Laboratory, California Institute of Technology \\ Pasadena, California 91109
}

\begin{abstract}
New shock compression data to $340 \mathrm{~kb}$ for single-crystal orthoclase (along (001)) demonstrate the onset of a shock-induced phase change at $\sim 115 \mathrm{~kb}$. Along the Hugoniot a mixedphase region extends to $\sim 300 \mathrm{~kb}$, above which the data are believed to correspond to the properties of a high-pressure phase having the hollandite structure (zero pressure density of $3.84 \mathrm{~g} / \mathrm{cm}^{3}$ ) reported by Ringwood et al. If the hollandite value for the zero pressure density is used, the zero pressure bulk modulus of this phase is approximately $2.8 \pm 0.2 \mathrm{Mb}$.
\end{abstract}

The very high pressure equation of state of orthoclase is of importance both in describing the effects of intense shock waves on potassiumfeldspar-bearing rocks on the earth and the moon [Hubbard et al., 1971; Drake et al., 1970; Chao, 1967; Kleeman, 1971; von Engelhardt and Stoffer, 1968] and in studying the earth's mantle. The latter is important because the orthoclase structure provides a model of the response of feldspar-bearing rocks to the high pressures of the earth's interior. Previously reported Hugoniot data for microcline [Ahrens et al., 1969a] demonstrated that this mineral, like plagioclase [McQueen et al., 1967], begins to transform to a new phase or phases at about $120 \mathrm{~kb}$ (along the Hugoniot). This phase change appears to go to completion for shock states above $\sim 300 \mathrm{~kb}$. Above this level the limited Hugoniot data for microcline suggested that the properties of a denser high-pressure phase were being sampled. The zero pressure density for the high-pressure phase inferred by Ahrens et al. [1969b] and Davies and Anderson [1971] of $\sim 3.5 \mathrm{~g} / \mathrm{cm}^{3}$ compares unfavorably and inconclusively with densities of 3.2 and $3.84 \mathrm{~g} / \mathrm{cm}^{3}$ expected for the possible high-pressure phases in the structures jadeite plus stishovite and hollandite. Because previous static high-pressure quenching experiments on both silicate and germanate (analog) potassium feldspar

\footnotetext{
${ }^{1}$ Contribution 2244, Division of Geological and Planetary Sciences, California Institute of Technology.
}

Copyright (C) 1973 by the American Geophysical Union. yielded only the hollandite-structured phase [Ringwood et al., 1967a, b; Kume et al., 1966] and because the inferred high-pressure phase assemblage density for granite [Ahrens et al., 1969b; Davies and Anderson, 1971] is consistent with the formation of the hollandite phase (in $\mathrm{KAlSi}_{3} \mathrm{O}_{8}$ ), we assume that this phase is produced in our experiments.

To further study the equation of state of potassium feldspar, a series of Hugoniot experiments were carried out on a suite of single crystals of orthoclase from Madagascar (Table 1). These single crystals possess perfect cleavage along (001) and distinct cleavage along (010) [Winchell and Winchell, 1951]. The samples were prepared by mounting and polishing the crystals in a parallel lapping jig on the (001) cleavage planes. Thin sections of the same orientation were also prepared for microscope observation. Under conoscopic observation all thin sections showed slightly off-centered optical normal figures, which confirm that the sample faces are parallel to the (001) cleavage [Deer et al., 1966]. The experimental procedure used in impacting these samples is described by Ahrens et al. [1971] and Ahrens and Gaffney [1971].

In most of the experiments at least two shock arrivals were recorded at the specimen free surface when shock waves were driven into the sample assemblies. For final shock states below about $300 \mathrm{~kb}$ these initial shock arrivals, which we believe represent finite-amplitude elastic shocks, have an average velocity of $7.39 \pm 0.06$ $\mathrm{km} / \mathrm{sec}$ (weighted mean and standard deviation). To substantiate this value, compressional 
TABLE 1. Orthoclase Formula Proportions

Element

Formula Proportion*

\begin{tabular}{ll}
$\mathrm{Na}$ & 0.022 \\
$\mathrm{Mg}$ & 0.0003 \\
$\mathrm{~A} 1$ & 0.192 \\
$\mathrm{Si}$ & 0.603 \\
$\mathrm{~K}$ & 0.180 \\
$\mathrm{Ca}$ & 0.00015 \\
$\mathrm{Fe}$ & 0.0030 \\
\multicolumn{1}{c}{ Total } & 1.003
\end{tabular}

Microprobe analysis by $\mathrm{A}$. Chodos (Ca1ifornia Institute of Technology). Orthoclase samples from Strongay, Madagascar.

*Based on eight oxygen atoms.

elastic velocity along the (001) direction was measured by ultrasonic interferometry [Spetzler, $1970]$ to be $7.53 \pm 0.02 \mathrm{~km} / \mathrm{sec}$. Ryzhova and Alexandrov [1965] measured the ultrasonic velocities of a series of potassium-sodium feldspars. Their reported value of compressional velocity along the (001) direction of a feldspar containing $78.5 \%$ orthoclase is $7.01 \mathrm{~km} / \mathrm{sec}$. Because the other components of the feldspar, anorthite and albite, have lower velocities than orthoclase, this value agrees in trend with our measurement. The free-surface velocities resulting from the free-surface reflection of this elastic shock were used to determine the amplitude (Hugoniot elastic limit, HEL) of this wave (via the free-surface approximation [Walsh and Christian, 1955]). Observed values lie between 41 and $91 \mathrm{~kb}$ (Table 2). The data (with the exception of shots 179 and 164) suggest that the HEL value is related to the final shock pressure, not unlike the situation in singlecrystal and polycrystalline quartz [Wackerle, 1962; Ahrens and Duvall, 1966]. For three shots with final shock pressures below $200 \mathrm{~kb}$ the average HEL value is $43.3 \pm 1.0 \mathrm{~kb}$. For shots with final pressures above this level a similar average yields $72.3 \pm 7.7 \mathrm{~kb}$ (weighted mean and standard deviation). The present HEL values bracket the earlier data for microcline.

Above the HEL the Hugoniot states (Table 2 and Figure 1), representing final shock states, were calculated by the impedance match method [Rice et al., 1958]. An intermediate (6.4-6.8 $\mathrm{km} / \mathrm{sec}$ ) velocity wave was observed for shots with final states above $300 \mathrm{~kb}$. We infer that this shock front was due to the phase transition and corresponded to a shock state of $\sim 300 \mathrm{~kb}$ and a density of $\sim 4.0 \mathrm{~g} / \mathrm{cm}^{3}$. The interaction of the elastic shock reflected at the free surface with the following second plastic shock was neglected. Figure 1 demonstrates that above $\sim 115 \mathrm{~kb}$ the Hugoniot states achieved all lie at a greater density than the Hugoniot state inferred from the extrapolation of Bridgman's [1948] isotherm (to $39 \mathrm{~kb}$ ) for orthoclase. These isothermal data were fit to a Birch-Murnaghan equation and yielded the zero pressure isothermal bulk modulus $K_{0 t}=539.5 \mathrm{~kb}$ and $\left(d K_{0 t} / d P\right)_{r}=4.4$. Similarly, the Voigt-ReussHill average of elastic constants for a series of potassium-rich feldspars reported by Alexandrov and Ryzhova [1962], Ryzhova [1964], and Ryzhova and Alexandrov [1965] gives a similar value for the (isentropic) bulk modulus $K_{08}$, which varies from 470 to $574 \mathrm{~kb}$. Isotherms based on the extreme values of the ultrasonic data are also shown in Figure 1. On the basis

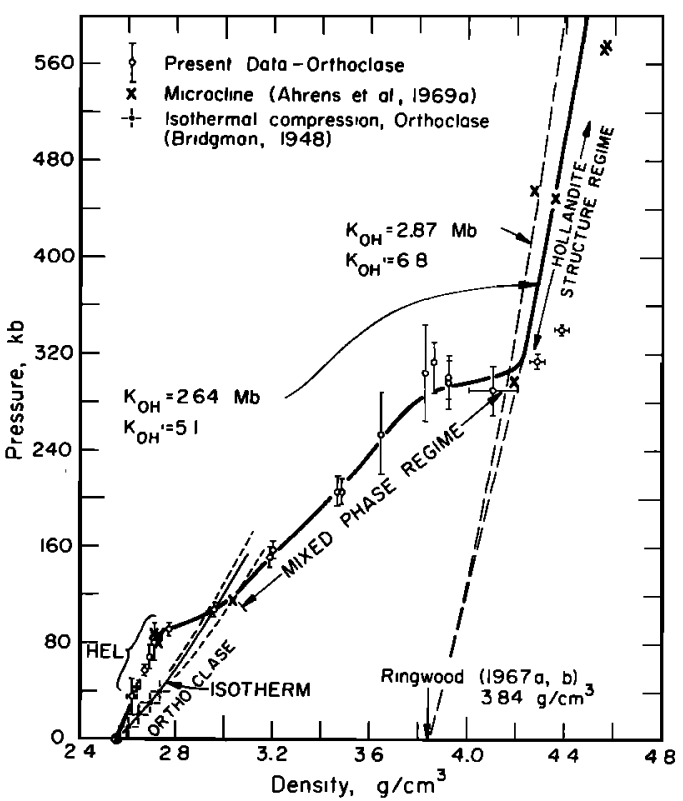

Fig. 1. Hugoniot data for single-crystal orthoclase. Shock data for microcline and the orthoclase isothermal compression data of Bridgman [1948] are also shown. Dashed curve above and below Bridgman's data represents the spread in bulk moduli observed ultrasonically for orthoclase-rich specimens by Alexandrov and Ryzhova [1962], Ryzhova [1964], and Ryzhova and Alexandrov [1965]. 


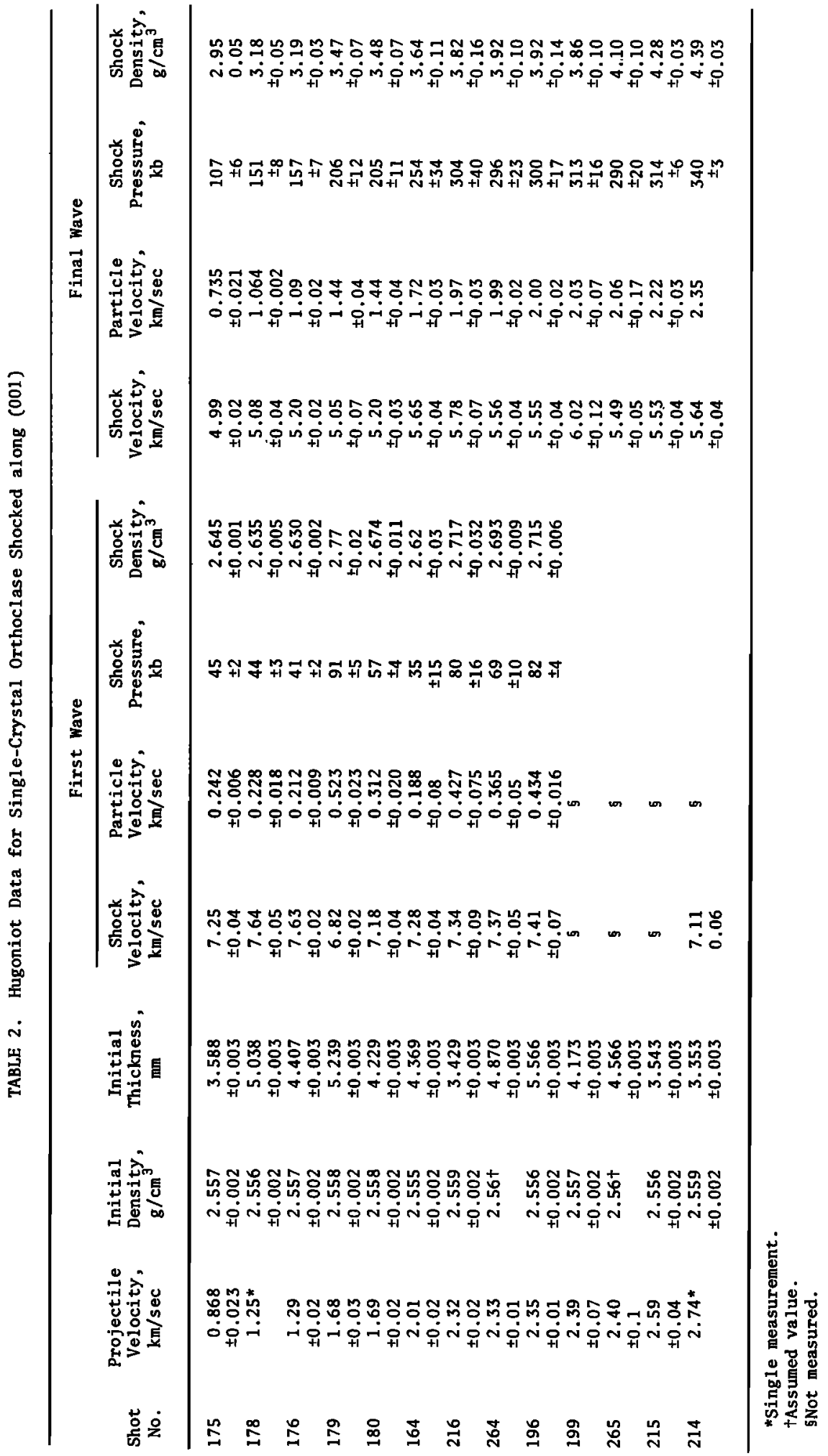


TABLE 3. Calculated Shock Temperatures in High-Pressure Regime

\begin{tabular}{|c|c|c|c|c|}
\hline $\begin{array}{l}\text { Density, } \\
\mathrm{g} / \mathrm{cm}^{3}\end{array}$ & $\begin{array}{c}\text { Hugoniot } \\
\text { Pressure, * } \\
\text { kb }\end{array}$ & $\begin{array}{c}\text { Isentropic } \\
\text { Pressure, }+ \\
\text { kb }\end{array}$ & $\begin{array}{c}\text { Hugoniot } \\
\text { Temperature, } \\
{ }^{\circ} \mathrm{K}\end{array}$ & $\underset{{ }^{0}}{\text { Isentropic }}$ \\
\hline $\begin{array}{l}4.1 \\
4.2 \\
4.3 \\
4.4\end{array}$ & $\begin{array}{l}233 \\
346 \\
472 \\
612\end{array}$ & $\begin{array}{l}226 \\
310 \\
401 \\
502\end{array}$ & $\begin{array}{r}465 \\
1138 \\
1912 \\
2795\end{array}$ & $\begin{array}{l}318 \\
325 \\
332 \\
338\end{array}$ \\
\hline
\end{tabular}

*Birch-Murnaghan fit: $K_{01}=2869 \mathrm{~kb}$ and $Y_{0}{ }^{\prime}=6.8$.
tCentered at zero pressure and $2988^{8}$.

of the intersection of the present orthoclase Hugoniot and the isothermal data at $115 \pm 10$ $\mathrm{kb}$ we infer that this pressure represents a minimum value for the onset for shock-induced phase change in orthoclase to the hollandite structure. This conclusion is based on the observations that the inferred pressure value for the transition agrees closely with the $120-\mathrm{kb}$ value (at $900^{\circ} \mathrm{C}$ ) obtained by Ringwood et al. [1967a, $b]$ for the formation of the hollandite-structured phase from sanidine and that the present $\mathrm{Hu}-$ goniot data, when they are taken with the earlier microcline results, imply a marked increase in the bulk modulus along the Hugoniot at densities greater than $\sim 4.1 \mathrm{~g} / \mathrm{cm}^{3}(\sim 300 \mathrm{~kb})$. The steep Hugoniot above $300 \mathrm{~kb}$ would presumably correspond to the properties of the hollandite structure. A minimum transition energy of 1.5 $\times 10^{10} \mathrm{ergs} / \mathrm{g}$ for

$$
\begin{aligned}
& \mathrm{KAlSi}_{8} \mathrm{O}_{8} \text { (orthoclase) } \\
& \qquad \mathrm{KAlSi}_{3} \mathrm{O}_{8} \text { (hollandite) }
\end{aligned}
$$

is implied by the observed transition pressure. In analogy to the case of shock compression of quartz and fused quartz [Wackerle, 1962; McQueen et al., 1963] we infer that the Hugoniot between $\sim 115$ and $\sim 300 \mathrm{~kb}$ represents a mixed-phase regime. Whether some phase other than the hollandite structure forms in this interval is uncertain; however, no other intermediate high-pressure phase or phase assemblage is currently known.

When the data of Ahrens et al. [1969a] are also used, a Birch-Murnaghan equation curve was fit through the eight raw Hugoniot data points, corresponding to the presumed high-pressure phase, by using a zero pressure density of 3.84 $\mathrm{g} / \mathrm{cm}^{3}$ [Ringwood et al., 1967a, b]. This procedure gives the parameters $K_{\text {on }}=2869 \mathrm{~kb}$ and $K_{0{ }^{\prime}}=6.8$. Excluding the lowest pressure, more uncertain datum at $290 \mathrm{~kb}$, yields $K_{\text {on }}=2637 \mathrm{~kb}$ and $K_{\text {on }}{ }^{\prime}=5.1$, which are our preferred values. Excluding the two highest pressure points from the fitting procedure yields $K_{\text {oh }}=2959 \mathrm{~kb}$ and $K_{\mathrm{oh}}{ }^{\prime}=6.6$. The sensitivity of these parameters to changes in the data indicates an uncertainty in the bulk modulus of the high-pressure phase of $\pm 8 \%$ and of some $15 \%$ in the value of $K_{\text {on }}{ }^{\prime}$. As a result both of using the new data and of making the outright assumption that the high-pressure phase has the hollandite structure, the bulk modulus obtained in this study is greater than that given by Ahrens et al. [1969b] by nearly a factor of 2 .

For application to the study of naturally shocked potassium feldspar in rocks subjected to hypervelocity input, it is useful to calculate a series of shock temperatures (Table 3 ). These are calculated by the method of Ahrens et al. [1969b]. A constant value of the product of the Gruneisen parameter and a density of 3.84 and a transition energy of $1.5 \times 10^{10} \mathrm{ergs} / \mathrm{g}$ was assumed. Although the equations of state of parameters of the high-pressure phase obtained in the present work are very different from those given by Ahrens et al. [1969a], the calculated shock temperatures, which depend critically only on the absolute increase in density upon compression, are rather similar to the earlier results.

Acknowledgments. We are grateful for the help of R. V. Gibbons, F. Hörz, and A. Chodos in obtaining and characterizing our samples and 
for that of D. Johnson, J. Lower, and H. Richeson in constructing and carrying out the experiments. This research was supported under NASA grant NGL-05-002-105 and NSF grant GA-21396.

\section{REFERENCES}

Ahrens, T. J., and G. E. Duvall, Stress relaxation behind elastic shock waves in rock, J. Geophys. Res., $71,4319-4360,1966$.

Ahrens, T. J., and E. S. Gaffney, Dynamic compression of enstatite, J. Geophys. Res., 76, 5504-5513, 1971.

Ahrens, T. J., C. F. Petersen, and J. F. Rosenberg, Shock compression of feldspars, J. Geophys, Res., 74, 2727-2746, $1969 a$.

Ahrens, T. J., D. L. Anderson, and A. E. Ringwood, The equation of state and crystal structures of high-pressure phases of silicates and oxides, Rev. Geophys. Space Phys., 7, 667-707, $1969 b$.

Ahrens, T. J., J. H. Lower, and P. L. Lagus, Equation of state of forsterite, J. Geophys. Res., $76,518-528,1971$.

Alexandrov, K. S., and T. V. Ryzhova, Elastic properties of rock-forming minerals, 3, Feldspars, Bull. Acad. Sci. USSR Geophys. Ser., 2, 129-131, 1962.

Bridgman, P. W., Rough compressions of 177 substances to $40,000 \mathrm{~kg} / \mathrm{cm}^{2}$, Proc. Amer. Acad. Arts Sci., 76, 71-87, 1948.

Chao, E. C. T., Shock effects in certain rockforming minerals, Science, 156, 192-202, 1967.

Davies, G. F., and D. L. Anderson, Revised shockwave equations of state for high-pressure phases of rocks and minerals, J. Geophys. Res., 76 , 2617-2627, 1971.

Deer, W. A., R. A. Howie, and J. Zussman, $A n$ Introduction to the Rock-Forming Minerals, p. 306, Longmans, Green, and Co. Ltd., London, 1966.

Drake, M. J., I. S. McCallum, G. A. McKay, and D. F. Weill, Mineralogy and petrology of Apollo 12 sample no. 12013; A progress report, Earth Planet. Sci. Lett., 9, 103-123, 1970.

Hubbard, N. J., C. Meyer, Jr., P. W. Gast, and $\mathrm{H}$. Wiesmann, The composition and derivation of Apollo 12 soils, Earth Planet. Sci. Lett., 10, 341-350, 1971.
Kleeman, J. D., Formation of diaplectic glass by experimental shock loading of orthoclase, $J$. Geophys. Res., 76, 5499-5503, 1971.

Kume, S., T. Matsumoto, and M. Koizumi, Dense form of germanate orthoclase $\left(\mathrm{KAlGe}_{8} \mathrm{O}_{3}\right), J$. Geophys. Res., 71, 4999-5000, 1966.

McQueen, R. G., J. N. Fritz, and S. P. March, On the equation of state of stishovite, J. Geophys. Res., 68, 2319, 1963.

McQueen, R. G., S. P. Marsh, and J. N. Fritz, Hugoniot equation of state of twelve rocks, $J$. Geophys. Res., 72, 4999-5036, 1967.

Rice, M. H., R. G. McQueen, and J. M. Walsh, Compression of solids by strong shock waves, Solid State Phys., 6, 1-63, 1958.

Ringwood, A. E., A. F. Reid, and A. D. Wadsley, High-pressure $\mathrm{KAISi}_{3} \mathrm{O}_{9}$, an aluminosilicate with sixfold coordination, Acta Crystallogr., 23, 1093$1095,1967 a$.

Ringwood, A. E., A. F. Reid, and A. D. Wadsley, High pressure transformation of alkali aluminosilicates and aluminogermanates, Earth Planet. Sci. Lett., 3, 38-40, $1967 b$.

Ryzhova, T. V., Elastic properties of plagioclase, Bull. Acad. Sci. USSR Geophys. Ser., 7, 633635, 1964.

Ryzhova, T. V., and K. S. Alexandrov, The elastic properties of potassium-sodium feldspars, Izv. Acad. Sci. USSR Phys. Solid Earth, 1, 53-56, 1965.

Spetzler, H. A., Equation of state of polycrystalline and single-crystal $\mathrm{MgO}$ to 8 kilobars and $800^{\circ} \mathrm{K}$, J. Geophys. Res., 75, 2073-2087, 1970.

von Engelhardt, W., and D. Stoffler, Stages of shock metamorphism in rocks of the Ries basin, in Shocic Metamorphism of Natural Materials, edited by B. M. French and N. M. Short, pp. 159-168, Mono Press, Baltimore, Md., 1968.

Wackerle, J., Shock-wave compression of quartz, J. Appl. Phys., 39, 922-937, 1962.

Walsh, J. M., and R. H. Christian, Equations of state of metals from shock wave measurements, Phys. Rev., 97, 1544, 1955.

Winchell, A. N., and $\mathrm{H}$. Winchell, Elements of Optical Mineralogy, p. 303, John Wiley, New York, 1951.

(Received November 14, 1972.) 